\title{
LOS LIBROS Y LA FORMACIÓN DE LOS ABOGADOS NEOGRANADINOS*
}

\section{Mónica Patricia Fortich Navarro**}

\author{
Fecha de Recibido: 4 de mayo de 2011 \\ Fecha de aprobación: 15 agosto de 2011 \\ Artículo resultado de Investigación
}

\begin{abstract}
Resumen
En este texto se presenta una breve reflexión sobre el proceso de formación de los juristas en el Nuevo Reino de Granada, para aproximarnos a los libros que fueron parte esencial de dicho proceso. La mirada arranca desde el contexto universitario en España, en aspectos como la oratoria forense, los estudios del latín, los colegios y algunas prácticas profesionales de los juristas, que luego se trasladaran al nuevo mundo, en donde tienen su propia lógica y problemas.
\end{abstract}

\section{Palabras clave}

Cultura del libro, bibliografía jurídica, libros y bibliotecas jurídicas, formación de juristas.

\section{THE BOOKS AND THE TRAINING OF LAWYERS NEW GRANADAN}

\begin{abstract}
This text presents a brief reflection on the process of formation for lawyers in the New Kingdom of Granada, for much closer to the books which were an essential part of that process. The gaze boots from university context in Spain, in aspects such as forensic oratory, the studies of the latin, schools and some professional practices of jurists, who then will be transferred to the new world where they have their own logic and problems.
\end{abstract}

\section{Keywords}

Book culture, legal literature, books and law libraries, training of jurists.

* Artículo de revisión correspondiente a un capítulo de la tesis doctoral denominada TOGADOS Y LETRADOS. LIBROS, LECTURAS Y BIBLIOTECAS EN LA FORMACIÓN DE LOS ABOGADOS NEOGRANADINOS (1739-1777) TOGADOS AND LAWYERS. Books, Reading and libraries IN THE FORMATION OF THE LAWYERS NEW GRANADAN REVOLUTIONARIES (1739-1777) en el marco del Doctorado en Sociología Jurídica e instituciones Políticas-Universidad Externado de Colombia.

** Abogada. Especialista en didáctica del lenguaje y la literatura. Universidad de Cartagena. Facultad de Ciencias Humanas. Magistra en Literatura hispanoamericana. Seminario Andrés Bello. Instituto Caro y Cuervo. Doctora en Sociología Jurídica e Instituciones Políticas, Universidad Externado de Colombia. Docente- investigadora de la Facultad de Derecho, Universidad Libre Bogotá. Correo electrónico: monicafortichnavarro@hotmail.com 


\title{
OS LIVROS E A FORMAÇÃO DOS ADVOGADOS DA NOVA GRANADA
}

\begin{abstract}
Resumo
Neste texto apresenta-se uma breve reflexão sobre o processo de formação dos juristas no Novo Reino de Granada, para aproximar-nos aos livros que foram parte essencial de dito processo. A mirada arranca desde o contexto universitário em Espanha, em aspectos como a oratoria forense, os estudos do latín, os colégios e algumas práticas profissionais dos juristas, que depois se transladassem ao novo mundo, em onde têm sua própria lógica e problemas.
\end{abstract}

\section{Palavras-chave}

Cultura do livro, bibliografía jurídica, livros e bibliotecas jurídicas, formação de juristas.

\section{INTRODUCCIÓN}

Un segmento de este acápite hace parte de la tesis doctoral denominada LETRADOS. LIBROS, LECTURAS Y BIBLIOTECAS EN LA FORMACIÓN DE LOS ABOGADOS NEOGRANADINOS (1739-1777) cuya pretensión es una aproximación al proceso educativo de los juristas en el Nuevo Reino de Granada a partir de los planes de caracterización del ambiente académico imperante en los principales centros educativos del virreinato.

La educación que recibían los abogados en el Nuevo Reino de Granada estaba sujeta a los lineamientos que para la fundación e implementación de cátedras, métodos y planes de estudios seguían las universidades españolas.(Rodríguez, 1973) El proceso se mantuvo hasta la segunda mitad del siglo XVIII cuando se empieza el movimiento ilustrado en cabeza del fiscal Moreno y Escandón, para la creación de una Universidad Pública, independiente del control de las órdenes religiosas que regentaban los Colegios Mayores y las universidades en todo el virreinato.

Las referencias históricas nos revelan el profuso movimiento en las prácticas judiciales de los estrados de la metrópoli. El dinamismo de las Reales Audiencias y las frecuentes alusiones a la superpoblación de abogados, de pleitos y de oportunistas que se confundían con los doctores de la ley en las grandes provincias, contrasta con los textos donde se intentaba organizar el quehacer de lo que se denominaba "jurisprudencia práctica," como correlato más cercano a lo que modernamente sería el derecho procesal.

\subsection{Metodología empleada}

El método es histórico-descriptivo, en una perspectiva socio-histórica que permitió una puesta en limpio de fuentes bibliográficas y documentales con las cuales se puedan elaborar nuevos trabajos de caracterización sobre la cultura del libro jurídico en el periodo colonial, en términos generales y de manera especial en la Nueva Granada, para llegar a propuestas sobre los flujos discursivos de ciertos libros.

El objetivo de la tesis era ambicioso, los resultados son modestos, pero corresponden a un primer momento de la exploración guiada por la estructura metodológica socio-histórico, descriptiva, compilatoria, absolutamente necesaria, para una recopilación cuantitativa (en el programa de Chartier), para abrir el camino a futuras investigaciones cualitativas, sobre la circulación y recepción de obras individualmente consideradas.

\subsection{Problema}

Las cuestiones básicas de la presente investigación, apuntan a revisar los procesos de circulación del conocimiento jurídico a partir de la pregunta: 
¿qué leían los abogados en el periodo colonial, anterior a la época de la independencia?. Dichas preguntas se proponían, para comprender los alcances en la formación de los juristas y sus aportes para un estado de derecho sólido y legítimo. Se trató de consolidar un corpus de textos que en la perspectiva bibliográfica abrieron la puerta a una visión de la historiografía jurídica como historia de los libros en derecho.

La investigación que se desarrolló, abordó nominalmente el siglo XVIII aunque en la práctica se hizo uso de información de todo el periodo colonial hispánico neogranadino. El marco histórico de 1739 a 1777 corresponde a dos eventos cronológicos que, nuestro modo, focalizan los movimientos ilustrados en el siglo XVIII. Por un lado, la organización de la estructura virreinal segunda (elección del virreinato de la Nueva Granada) y por otro, la creación de un espacio físico para la difusión del saber: la Real Biblioteca de Santafé, desde donde apoyar el regalismo y hacer circular los saberes esenciales, para sostener el orden de las ciudades letradas.

\subsection{Conclusiones}

En relación con este capítulo y en el marco general de la tesis, las conclusiones conducen a expresar un número de textos considerados básicos en el proceso de formación de los juristas, menor al número de textos que circulaban en todo el periodo colonial y eran tenidos como piezas esenciales del derecho canónico y civil. En los planes de estudio que se seguían, las recomendaciones de textos básicos no pasaban de ser unas decenas de obras distribuidas entre las dos jurisdicciones. Es más frecuente encontrar en los inventarios, las obras del derecho canónico, que las del civil.

- Los abogados en la colonia neogranadina tenían una formación deficiente apoyada en una gran dispersión de textos, en especial, de la llamada jurisprudencia práctica. Los criterios de selección de tratadistas, en su mayoría comentadores de los cuerpos y compilaciones como el Corpus Juris Civilis, dependían de la liberalidad de los catedráticos o lectores. El control de las bibliografías de algunos planes de estudios, seguía en teoría los lineamientos de Salamanca o Alcalá, aunque en la práctica la única y más fuerte referencia fuesen lo mamotretos.

- Por los títulos y en atención a su contenido y autores, la mayoría de las obras del periodo corresponde a textos que representaban el pensamiento ortodoxo, para fortalecer el poder del monarca y formar un jurista fiel y obediente de los órdenes trazados por la corona, para conjurar los males públicos y garantizar la completa subordinación de todo el pueblo.

- La tendencia al uso de textos manuscritos elaborados por los catedráticos o lectores de los colegios mayores y las universidades, es un factor que suplantó la circulación de títulos. Las prácticas como el dictado y la formación de mamotretos o textos manuscritos de autores propios, permitió que los contenidos de los textos hubieran sufrido procesos de deformación conceptual, incidiendo en las prácticas y en un aurea de mediocridad para muchos abogados.

- Algunos textos que fueron editados en siglo XVIII no tuvieron circulación masiva, bien por las restricciones del Índice o por el conocimiento que los autores y catedráticos locales tuvieran de los mismos: de hecho no encontramos registros físicos de obras como las de Filangieri, o Bielefeld. Este último, no figura en ninguna de las bibliotecas físicas, a pesar de haber sido un texto recomendado como básico, en el Plan de estudios para la jurisprudencia del Fiscal Moreno y Escandón en 1774.

- Muchas obras consideradas, en su época, como textos básicos para la formación de los abogados, no aparecen en los registros físicos, (corpus material) y aun cuando ello pueda deberse a que pertenecían a colecciones privadas de juristas, lo cierto es que no hay una prueba de su circulación material, ni una relación con su contenido, en textos 
producidos por autores locales, por lo menos en el caso de la Nueva Granada.

\section{LAS FACULTADES DE DERECHO Y LOS ESTUDIOS EN ESPAÑA}

Los gremios y las asociaciones de abogados van a permitir unificar criterios sobre sus prácticas, pero existen varias tesis sobre su origen colegiado, porque si bien existían sociedades de mutuo apoyo, los colegios eran una realidad legislada en el siglo XVIII. Sin embargo, el tema de las facultades para los estudios de derecho, se puede constatar más claramente con la aparición de las Cathedras. Las cátedras van permitir la evolución en la tradición del derecho romano, en virtud a la introducción de una cátedra de derecho civil, y otra de derecho patrio.

En este apartado, no se desarrolla sistemáticamente un panorama de los estudios jurídicos en España y en los demás virreinatos (Ruíz, 1997), sino, que se abre la revisión de varios fenómenos asociados a ella como la oratoria forense, la práctica profesional y algunas normas dispersas en diferentes compilaciones, que dejan ver la forma como se regulaba el ejercicio de los abogados y su formación. De hecho, sobre este aspecto habrá permanentes referencias a lo largo del trabajo.

La mayor parte de la responsabilidad sobre la educación de seglares y religiosos, fue un asunto del clero, ello no varió en el caso de los abogados neogranadinos. En armonía con nuestro planteamiento, es posible constatar este hecho en la revisión de las colecciones de las bibliotecas de Clérigos, como el caso del mismo Arias de Ugarte, desde el siglo XV o el también arzobispo-virrey Caballero y Góngora a finales del siglo XVIII. Sobre este aspecto el franciscano Francisco Quevedo, afirma que gran parte del esfuerzo de formación se debe al Colegio Mayor del Rosario:

Toda la enseñanza estuvo monopolizada por los centros religiosos; incluso la enseñanza humanista. Naturalmente que nadie como ellos disponía de medios formativos. El traslado de religiosos venidos de Europa estaba vinculado al equipaje de libros y de manuscritos de autores notables. Es sorprendente el número de libros depositados en la Biblioteca Nacional pertenecientes a las órdenes religiosas (...) En menor cantidad los libros de Derecho y humanidades. Ellos constituyen el documento más auténtico de las corrientes teológicas neogranadinas. Santafé seguía fielmente la pauta de las universidades europeas, sobre todo españolas; su preferencia por la Teología tanto dogmática como moral. (Quevedo, 1953, pp. 7-8)

El cronista Ignacio Gutiérrez al referirse a la cultura literaria de Santafé de Bogotá, citando a Méndez Pelayo, dice es tan antigua como la conquista. A la cabeza está el ilustre jurista, fundador de Bogotá, "bizarro abogado cordobés Gonzalo Jiménez de Quesada" y al papel, una vez más, de los centros de formación religiosa a finales del siglo diecisiete:

Ya a fines del Siglo XVII contaba la ciudad con estudios universitarios, los cuales estuvieron primeramente en el convento de Santo Domingo, pero luego se crearon los de Santo Tomás, y por último el Arzobispo Fray Cristóbal de Torres fundó el Colegio Mayor de Nuestra Señora del Rosario, en el cual eran admitidos como nobles los hijos de los caciques e indios principales; podía estudiarse en él gramática, filosofía, teología, cánones, jurisprudencia y medicina. La cultura, si en conjunto no era superior a la de México, la igualaba en muchas de sus manifestaciones y sobresalía en algunas de éstas. ${ }^{1}$

1 Gutiérrez Ponce, Ignacio. Las crónicas de mi hogar o apuntes para la historia de Santafé de Bogotá. cap. XXIV convento de Capuchinos. Terremotos de 1783, la jura de Carlos IV, Fiestas Reales. En: Papel Periódico Ilustrado. Tomo III, Bogotá: Imprenta de Silvestre y Compañía ,1883-1884. p.3-4 
El rol de las universidades neogranadinas hasta el siglo XIX, era más de juntas examinadoras para conferir títulos a los estudiantes egresados de los Colegios Mayores, que de centros de formación académica, siendo los dos más importantes el Colegio mayor del Rosario y el Colegio Mayor de San Bartolomé. El primero fundado inicialmente por dominicos y el segundo por jesuitas. Además, de la Universidad de Santo Tomás; por fuera de la capital del virreinato, se destacan el Seminario de San Carlos de Cartagena y el seminario de Popayán, de donde se eliminaron los cursos de formación en derecho:

\section{(...) en el Seminario de San Carlos de} Cartagena, del que en 1790 la corona eliminó los cursos de derecho para la obtención de grados en Bogotá y, posiblemente, algunos cursos de derecho dictados en el Seminario de Popayán antes de 1791. Luego de la expulsión de los jesuitas se barajaron planes dirigidos a la creación de la universidad pública (Gómez, 1989), pero el proyecto no tuvo realización e incluso durante los primeros años de la república la Universidad tomista siguió, como lo hizo de manera exclusiva durante la colonia, examinando y confiriendo grados a quienes lo solicitaran, hasta que la ley de 18 de marzo de 1826 puso fin a la junta examinadora de los dominicos. (Young, 1994, p. 38).

De acuerdo con Julio Gaitán, el balance general de los centros de formación y examinadores, al final del periodo colonial, (1810) es de dos colegios en Bogotá, dos en Quito y uno en Caracas. Mientras que en Cuenca, Panamá, Cartagena, Santa Marta, Popayán y Mérida, funcionaban colegios seminarios en los cuales se formaban novicios y seglares. En 1804 una Cédula Real aprobó la fundación de una universidad en el colegio de Mompox, que contemplaba cátedras de leyes y cánones.

En su estudio sobre la enseñanza en el Colegio Mayor del Rosario, destaca como nota predominante la religión, en términos de control de las cátedras existentes y del número de los catedráticos. En la segunda mitad del XVII con la fundación de este Colegio (1653), hay un claro propósito de formar al sector secular de origen español, en virtud de las cátedras de Teología, Derecho Canónico, Civil, y Medicina. El 56 por ciento de las cátedras correspondía a formación religiosa, no obstante los tropiezos que enfrentaron, para la creación de las respectivas facultades:

(...) de 95 catedráticos encontrados -23 de filosofía, 33 de teología, 22 de derecho canónico, 10 de derecho civil, dos de medicina, uno de matemática y cinco de gramática- 55 corresponden a la facultad de Teología y de derecho canónico. ${ }^{2}$

El rol de los catedráticos estaba restringido en unos límites precisos, en donde se especificaban el conjunto de textos y comentaristas a los textos, los estatutos y reglamentos de las instituciones y la adhesión a una determinada doctrina, de acuerdo con los parámetros de la lectio, la dictatio y la disputatio. En su orden lectura en "viva voz" y dictado para ser tomado con rigor, al lado de explicaciones o glosas de los textos. Luego, las discusiones retóricas donde el ganador era quien mejor y más fiel mantuviera la teoría al criterio de la autoridad. Lo que fomentaba el principio de autoridad, la transmisión de un saber fijo y superaba los inconvenientes de los pocos libros de texto, en un círculo de repetición y obediencia:

(...) esta forma de enseñanza "de viva voz" que se remontaba a la Edad Media, se presentaba como necesaria ante la ausencia de textos y favorecía la elocuencia, esto es, la Teatralidad; además se apoyaba en la memoria, con base en repetición. Ahora bien, la lectio no se limitaba a los libros de texto, sino a los comentarios. Es decir, sobre las formas previamente institucionalizadas

2 Para mayor documentación se recomienda la consulta de Jorge Tomás Uribe Ángel. Historia de la Enseñanza en el Colegio Mayor del Rosario 1653-1767. Bogotá: ed. Universidad del Rosario, p. 29 
ni siquiera el alumno podía expresar su opinión, sino que los comentarios se hallaban institucionalizados. ${ }^{3}$

Como un paralelo para revisar la formación de los abogados neogranadinos, está la descripción de la formación jurídica en Venezuela. Tulio Chiossone afirma que la mayoría de las actividades judiciales de la colonia, se recogen en las Reales Audiencias, que impulsaban el desarrollo de la profesión y de la magistratura. Antes de la Creación de Real Audiencia de Caracas (julio 19 de 1787) había en la ciudad Bachilleres en leyes, abogados y doctores en Derecho, en buen número, que ejercían la profesión en "estudios" o bufetes y hacían pasantías en la Audiencia: los egresados de la Universidad Real y Pontificia de Caracas y del Seminario de San Buenaventura de Mérida. A pesar de no estar desarrollado un derecho procesal, hubo una primera instancia en los juicios, sustentados en las normas de las leyes de Indias:

Las leyes que se aplicaron en los procesos criminales fueron las Siete Partidas y la Nueva y Novísima Recopilación, pues las Leyes de Indias, aunque sí establecían penas, no crearon tipos delictivos especiales. La Real Audiencia como tribunal de Apelación, no tenía la específica función de moderar la pena, pero sí lo hacían en algunos casos (...) (Chiossone, 1980. p. 114)

La manera como se producían los fallos y la forma de darlos a conocer, se resume en cita que Chiossone, hace de Héctor García Chuecos, en donde muestra la estructura de las "Reales provisiones":

Los mandatos, resoluciones y sentencias de la Real Audiencia se transcribían a las personas interesadas, a las encargadas de

3 Ibíd., p. 74. Expresa como a la lectio, la dictatio y la disputatio, se le sumaban las formas medievales de formación básica que debían implementar las universidades, la Trivium, comprendida por la gramática, retórica y dialéctica, y la Cuadrivium: aritmética, geometría, música y astronomía. darle cumplimiento y a las que por especial disposición del Tribunal debían conocerlos. Estas transcripciones se agrupaban bajo el nombre genérico de Reales Provisiones y contenían: $1^{\circ}$.el libelo; $2^{\circ}$. La representación del Fiscal, y $3^{\circ}$. El fallo del tribunal. De las obligaciones de orden procesal apenas se hacía mención (...)(Chiossone, 1980)

También hace referencia a la severidad y exigencia para otorgar los títulos, porque la Audiencia de Caracas los expedía previa comprobación de aspectos como el lugar de nacimiento, la limpieza de sangre, la certificación de "Vita et moribus", los juramentos e inscripciones en el Colegio de Abogados, condiciones que en la Nueva Granada, serán igualmente esenciales, para garantizar el linaje de la organización de una elite burocrática, conforme se analizará más adelante. Del mismo modo, hace alusión a los Controles que ejercía la Corona para restringir el número de abogados que llegaban a las indias.

\section{LA ORATORIA FORENSE DE LOS ABOGADOS}

En un estudio sobre los datos relativos a la formación de la oratoria forense en los tribunales españoles, hasta el siglo XVIII, es necesario citar las ordenanzas reales de 1692 dirigidas a los abogados. Se trata de las ordenanzas de unos de los colegios más antiguos de España, es decir, el Colegio de Valladolid, aprobadas para los abogados que prestaran servicios en las Cancillería de las Audiencias. En esa época, se da impulso a la figura del Fiscal y su ministerio, en virtud del establecimiento de las Cancillerías y los Tribunales Superiores Permanentes, por mandato de los reyes católicos. Fue en 1594 donde se introduce como novedad en la organización de la profesión, que ninguno pudiera abogar en el consejo del rey, ni en los demás tribunales, sin que fuera examinado y aprobado por los miembros del consejo y los oidores de las Audiencias, al tiempo que no podía ejercer funciones sin estar inscrito en la matrícula de abogados. De acuerdo con Arturo Majada en el Fuero Real y 
en las Partidas, aparecen disposiciones sobre los abogados sin mayores informes sobre la oratoria, en los tribunales de la época:

Parece exacto el juicio de que poco podría exigirse en aquel Foro cuando la instrucción de sus profesores estaba reducida al desordenado y superficial estudio de la legislación romano-canónica, sin conocer la historia de las leyes españolas, sin estudios accesorios de literatura y sin conocimiento exacto del derecho patrio. (Majada, 1962, p. 42)

Mientras en Francia es significativa la influencia en el Foro y en el estilo judicial, del clasicismo y las letras de los autores de gran relieve, en España el foro está lejos de los influjos del Siglo del Oro literario y del movimiento renacentista, no permeando a los abogados que están imbuidos en los textos latinos y en el estilo farragoso del culteranismo. A pesar de la formación teológica, y filosófica exhibida en el concilio de Trento, los abogados producían libros basados en los postulados filosóficos imperantes: "(...) produciendo (...) abundantes y preciados libros, no sólo de teología, de poética $y$ de literatura en general, sino de Derecho Natural y Público y de Jurisprudencia canónica y civil" (Majada, 1962)

Los rastros sobre elocuencia forense son pocos y los escritos sobre defensas, y alegatos fiscales, en los archivos, sobre todo en el Consejo de Castilla muestran abogados con estilo confuso, poca claridad en la construcción de las frases, sin formación literaria, con abuso de citas y exceso de erudición indigesta e inoportuna. Según Majada, en el reinado de Felipe III y Carlos II, no se mencionan abogados brillantes por sus defensas orales o escritas, solo hasta la reacción de los tratadistas en el reinado de Fernando VI y Carlos III se produce un giro en la jurisprudencia española:

Con la favorable influencia que ejerció en nuestro idioma la escuela clásica que floreció desde mediados del siglo, con la reacción operada en la república de las letras, mejoró en alto grado el estilo forense, se introdujo entre abogados y fiscales el buen gusto literario que es elemento tan esencial en el arte de la palabra y brillaron oradores como el Conde de Campomanes, Meléndez Valdes, Jovellanos, Pérez Camino y Rojas Cortés. (Majada, 1962)

Como testimonio de esa preocupación por la praxis profesional de los juristas, encontraremos en los planes de estudio y en las disposiciones sobre las cátedras de los bachilleres y doctores, la obligación de aprobar los cursos de gramática y retórica, para ponerlos al servicio de la formación de los futuros abogados.

\section{LOS ESTUDIOS DE LATÍN Y LAS CÁTEDRAS DE DERECHO}

De acuerdo con Rivas Sacconi, el latín es la lengua que permite el acceso a los estudios en las facultades superiores. Los planes de estudio son seguidos bajo los parámetros de España y en la lógica del sistema medieval clásico de las siete artes liberales del trivium (gramática, oratoria, dialéctica) y el cuadrivium (astronomía, aritmética, geometría y música) y la Ratio Studiorum. Después de la Escuela de Primeras letras, la enseñanza comprendía tres partes: Gramática y Retórica, Artes o Filosofía y luego las facultades mayores: Teología, Cánones (derecho eclesiástico), Leyes (jurisprudencia civil) y Medicina. Los grados que se podían recibir en las universidades eran los de: Bachiller, Licenciado, Doctor y Maestro, el primero se alcanzaba en la adolescencia y el de doctor antes de los veinte años, de allí, dependiendo de los estudios, se podía hacer carrera en el magisterio o en la cátedra (como lectores). En general, el latín estaba en todo el proceso de formación, y, después de leer y escribir, era la tarea más importante que tenía que asumir el estudiante para avanzar:

El latín era la fábrica intelectual resultante del abigarrado conjunto de universidades, seminarios, colegios, conventos y escuelas, $y$ de disposiciones legales y prácticas escolares, 
como espíritu vivificador que ha de animar todo organismo y ponerlo en movimiento. Entre aquellas instituciones materiales y jurídicas, el latín es omnipresente: lengua oficial de la escuela, lengua literaria y científica por excelencia. (Rivas, 1995, p. 56)

En las universidades europeas y en las de las indias, las clases de las facultades mayores se exponían en latín de forma obligatoria. Los lectores o catedráticos dictaban sus clases en esa lengua, a excepción de los de artes, que podían usar la lengua Romance para poner ejemplos y en el derecho, especialmente, para citar leyes españolas. Según Rivas, tal obligatoriedad estaba de acuerdo con los estatutos de la Universidad de Salamanca de 1538 "item estatuímos y ordenamos que los lectores sean obligados a leer en latín(...) excepto refiriendo alguna ley del reyno o poniendo exemplo” (González, 1980, p. 64)

Los textos eran, igualmente, en latín y no siempre de libros impresos sino de notas tomadas bajo el dictado del catedrático (dictados o mamotretos), en virtud de la imposibilidad de conseguir suficientes libros para cada estudiante, y el deseo de los docentes de ser autónomos con las cátedras. De hecho, Rivas Sacconi anota como de manera subsidiaria, ellos señalaban un autor para el estudio, aunque cada Colegio tenía su propia biblioteca de acuerdo con las materias y la mayoría de los textos estaban en latín, lo que en caso del derecho puede verificarse cuando se revisan los títulos existentes, en las bibliotecas que transcribimos, en su gran mayoría de autores y en lengua latina. Dentro y fuera de los colegios había una intensa vida intelectual y muchas oportunidades para mostrar los conocimientos y la formación en latín, verbigracia, los certámenes, la inauguración y finalización de cursos, grados y oposición de cátedras, entre otros. La emulación de conocimientos era una fuente de trabajo intelectual y las rivalidades entre los colegios, como la que existía entre San Bartolomé y la del Rosario, les daba mayor brillo.

Algunos autores proponen que se relajaron las normas que prescribían el uso del latín, y que éste se limitaba a los actos académicos. Pero, Rivas observa que en el virreinato de la
Nueva Granada, las normas se cumplieron con puntualidad hasta finales del setecientos. En una cita de una norma de la Novísima Recopilación de las leyes de Indias, una disposición de Fernando VI en 1753 declara que en:

“(...) todas las Universidades de estos Reynos, que los maestros, profesores y estudiantes no hablen ni disputen dentro de los patios y aulas sino en lengua latina" (p. 21).

Por otra parte, en su capítulo sobre los "Tratados didácticos" Rivas anota como los textos latinos que se empleaban en los siglos XVII y XVIII, son la mejor comprobación del uso de esa lengua. El dictado, era la forma como se conformaban los Mamotretos, unas veces hechos por los profesores y otras por los mismos estudiantes, y como resultado de la lectura In voce. El catedrático organizaba sus mamotretos, que en la gran mayoría de los casos eran obras mediocres y elementales, razón por la que muchos reclamaban que la enseñanza se hiciera con los libros impresos. En la Biblioteca Nacional, se encuentra buena parte de los libros provenientes de los colegios de las órdenes religiosas, que junto a los del Colegio del Rosario son la muestra del latín universitario de la Nueva Granada. En gran número se encuentran los de filosofía y teología y muy escasos los de derecho y humanidades, los libros primeros son producidos en el Colegio Mayor del Rosario y de San Bartolomé, con maestros como el javeriano Martínez de Ripalda y en el caso de materias jurídicas, textos como el tratado De iurisdictiones de Juan Antonio de Oviedo y Rivas en 1645, oidor de la Real Audiencia de Santa Fe. ${ }^{4}$

En el campo de la Dogmática y el derecho eclesiástico, se destacan la obra del agustino Padre Agustín de Caycedo y Velasco O.S.A. en $1707^{5}$ y la obra del jurisconsulto Gabriel

4 Ibíd., p.120. Ad perdifficile elegansque Papiniani responsum in L. I. de officio eius cui mandata est iurisdictio laconica et utilia scolia, aut...ad tractatum de iurisdictione, anno 1644, s.

5 Ibíd. p. 188. Expugnatio apellationis, vel appellantis a decreto et executione decreti Eminentissimi Cardinalis Patriarchae Antiocheni, Commissarii et Visitatioris Apostolici, cum potestate Legati a latere in Regno 
Álvarez de Velasco, oidor de la Real Audiencia de España que trae consigo una profusa biblioteca. Así mismo, se exalta el trabajo de Álvarez de Velasco porque reimprimió y adicionó la obra de Simón Vaz Barbosa, bajo el título Axiomata iuris (1631), además de las dos primeras partes del tratado De privilegiis pauperum et miserabilium personarum (1630) y la tercera parte en 1636 cuando viaja hacia Santa Fe; estando aquí, preparó una segunda edición de su obra en dos partes y los estudios denominados De iudice perfecto (1662) y De alimentis y otros textos que, según Rivas no se imprimieron.

Se destaca la obra del momposino Juan Suárez de Mendoza (1681), quien se formó en la escuela de Salamanca en los dos derechos, bajo la dirección de consagrados maestros salmantinos, entre ellos Francisco Ramos, cuyos textos son vitales en su proceso. Suárez aspiró a la docencia, pero fue designado para la magistratura y fue nombrado Oidor en la Chancillería de Valladolid y en la Casa de Contratación de Indias, en Sevilla, desde donde conoce muchas causas sobre el nuevo mundo. Después fue ordenado sacerdote, pero cuando aspiraba a las cátedras jurídicas preparó la obra Ad Titulum Digestorum ad legem Aquiliam commentarium $^{6}$ (Salamanca 1640). Otro jurisconsulto neogranadino es José Merlo de la Fuente (1709), oidor de la Real Audiencia de Santa Fe, quien reunió sus dictámenes en este tribunal bajo el título latino Vota decisiva, uidicialiter prolata in Regio Santae Fidei in Novo Granatensi Orbe Supremo Senatu. ${ }^{7}$, cuyo contenido está en castellano, con breves referencias en latín.

Chinarum, D. Caroli de Tournon, emanate die 25 lanuarii 1707 (El nombre completo en Latín, de las obras se cita raramente en los inventarios, ese será un elemento que dificulte su identificación plena, en virtud a que varias obras podían citarse en su forma abreviada, de manera similar.

6 Ibíd., p. 206

7 Ibíd., p. 207 el título completo es: Vota decisiva, uidicialiter prolata in Regio Santae Fidei in Novo Granatensi Orbe Supremo Senatu. Opus licet non specialiter novum nec tritum in Chancellariis Indiarum. Necessarium quidem ac omnibus in foro versantibus apprime utile

\section{LOS COLEGIOS DE ABOGADOS Y LA FORMACIÓN DE LOS PROFESIONALES}

La organización y creación de Colegios de Abogados en España es un fenómeno del Siglo XVIII, sin embargo, desde la edad media surgen asociaciones o agremiaciones de personas en razón de oficios o artes para ayudarse mutuamente, ellos se forman en lugares como Barcelona, o en Zaragoza en 1546, y sucesivamente en Valladolid, Sevilla, Valencia y La Coruña. Una mirada mucho más profunda revela como en el imperio romano existían los colegios de abogados, o corporaciones llamadas Ordo o Collegium Togatorum., ${ }^{8}$

Los Collegium romanos fueron el espacio para el desarrollo de la profesión de juristas como Catón, los Gracos, Scipión y Delio en la primera época, Antonio y Cicerón en la segunda. Según Iglesias Corral, en las primitivas leyes de Castilla y en los antiguos fueros, aparece la figura del Abogado, sin la organización corporativa o colegiada. Lo mismo ocurrirá en Las Partidas, las Ordenanzas de Montalvo, las Ordenanzas de los Abogados — de los Reyes Católicos-y la Novísima Recopilación, entre otras, que se ocupan de las actividades de la Abogacía, pero no de su organización corporativa:

Cuando antes de las Partidas se habla de los Abogados y voceros, no se debe creer que se alude a los Abogados tales como se conocen después de este Código, sino que eran hombres buenos que defendían a los vecinos, que por sus cortas luces, por enfermedad $u$ otros motivos no podían hacerlo por sí mismos. Las Partidas vienen

8 Historia de los Colegios de Abogados de España. Conferencia del Excmo. Sr. D. Manuel Iglesias Corral en el Ilustre Colegio de Abogados de Málaga con motivo de su bicentenario. Manuel Iglesias Corral Decano del Ilustre Colegio de Abogados de La Coruña de 1963 a 1988.Día 15 de octubre de 1976. Versión digital consultada el día Marzo 18 de 2009, http://www.icacor.es/sp/pages/menu. asp?pag $=19 \& u r l=0 \&$ nodo $=17$. cfr. Peréz Bustamante, Rogelio. El ilustre Colegio de Abogados de Madrid 15961996. En: Barcia Lago, Modesto. Abogacía y ciudadanía. Madrid: Dykinson, 2007 
a hacer de los Abogados o voceros un oficio público, exigiendo condiciones, estableciendo prohibiciones y disponiendo expresamente en la Ley XII el recibimiento de los Abogados, por los mismos tribunales.

Será hasta los siglos XII y XIII que se descubran los antecedentes de los Colegios en los Privilegios reales de 1295 y 1333 , documentos conservados en el Archivo de Aragón, que consolidan el Colegio de Abogados de Barcelona. El autor muestra como el siglo XIII, el derecho Romano es retomado por los juristas del Ius Novum, del esplendor de la Escuela de Bolonia, de Santo Tomás y las órdenes mendicantes, el final de las Cruzadas, San Francisco de Asís, Aristóteles de la mano del Islam y de las Partidas. Además, señala como el influjo de los principios canonistas de las Partidas, de corte románico, será el antecedente de otros colegios como el de Zaragoza, mediante el ordenamiento jurídico de Sancho IV y como consta en una escritura de 1546, allí existía la "Cofradía de Letrados del Señor San Ivo", antecedente del "Real e Ilustre Colegio de Abogados de Zaragoza".

En Valladolid en 1592 se forma una Hermandad y Cofradía de Abogados, en Madrid en 1595, se erige en la iglesia de San Felipe el Real, de la Orden de San Agustín, su Congregación y en 1732 se convierte en el Colegio. Según, Fernández Serrano, citado por Iglesias, refiere que continúa en antigüedad el Colegio de Sevilla (1706), Valencia (1759), La Coruña, (1760) y Málaga en 1776. Sin embargo, el autor destaca como en los "Estatutos y Ordenanzas del Ilustre Colegio de Señores Abogados de la Real Audiencia de la Ciudad de La Coruña, Reyno de Galicia, nuevamente establecido en el año de 1760 revela: "la existencia de una organización profesional gallega es anterior a la fundación de la Audiencia de Galicia por los Reyes Católicos, establecida por Real Cédula de 3 de agosto de 1480". ${ }^{9}$

9 Ibíd. Cfr. Con las anotaciones de Sánchez Ventura y Pascual en su obra "La Seguridad Social de la Abogacía”. Referencia citada por Iglesias Corral.
A pesar que desde el siglo XII existen gremios, cofradías y hermandades, en buena parte antecedente de los "colegios", en el caso de los abogados se menciona la negativa a identificarse en dichas asociaciones por su parecido con gremios de artesanos, o comerciantes, en virtud de que ellos se sentían más cercanos con la nobleza y el clero. De hecho, se comenta que en sus orígenes los juristas se reunían bajo el amparo de la figura eclesiástica del "patrono" y no por intereses económicos, de mutua ayuda o en asuntos comunes. La vinculación eclesial estaba marcada, de hecho, realizaban sus funciones y reuniones en las iglesias.

Iglesias Corral cita autores de la época, que señalan como desde el siglo XI surgen Colegios (El Colegio de Artistas, la Cofradía o hermandad de Cambiadores, la Cofradía del Cirial, la Cofradía de los Azabacheros, etc.); también se discute acerca de la sinonimia de los términos Cofradía y hermandad (López Ferreiro) y como en otras ocasiones tenían acepciones diferentes (Tramoyeres). Hubo varias resistencias históricas al proceso de formación de las Cofradías o hermandades, entre ellas las de Fernando III, quien luego las mandó a disolver y en otros casos a limitar sus funciones. Las Partidas controlan a los profesionales del Derecho y niegan la posibilidad a las agremiaciones. En las Cortes de Sevilla (1250), Jerez (1269) y Valladolid (1268), hay oposición a las asociaciones profesionales. Finalmente, en 1617 mediante un auto acordado del Consejo de Castilla hace obligatorias las agremiaciones "para que los letrados puedan ejercer en la Corte". Según el autor, en esta disposición de carácter obligatoria reside la razón de ser y la existencia de los Colegios.

Por otra parte, se propone como antecedente de la legislación de la profesión en España, la obra legisladora del Rey Alfonso X, cuando, primero con el Fuero Real y luego con Las Partidas, intentó superar el localismo jurídico de la Alta Edad Media. Dedicó el monarca quince leyes de la Tercera Partida a ordenar la labor y la figura del abogado o Bocero y lo define como: «Ome que razona por otro en juicio, o el suyo mismo, 
en demandando o en respondiendo. Easí nome porque con voces e con palabras usa de su oficio». Esta codificación es la primera en separar las tareas de defensa y las de representación. ${ }^{10}$

Para Martínez de Mañana, la abogacía en la edad media se regía por el Código Alfonsino hasta que los Abogados pudieron entrar a formar parte del Consejo Real por las Cortes en 1480, donde se regularon sus actividades profesionales mediante Las Ordenanzas de Abogados y Procuradores promulgadas en Madrid el 11 de febrero 1495, por los Reyes Católicos.

\section{LA PRÁCTICA PROFESIONAL DE LOS ABOGADOS NEOGRANADINOS}

Cientos de archivos del fondo sobre abogados, relacionados con su práctica profesional, dan cuenta de los procedimientos de la época, para pedir a la Real Audiencia de Santafé, les permitiera ser recibidos como abogados para el ejercicio, además de las solicitudes sobre la aprobación del plan de estudios, su idoneidad y méritos, el reconocimiento para ejercer en una plaza diferente a su lugar de origen y la admisión al Colegio de Abogados de Santafé. ${ }^{11}$

Podemos revisar los contenidos y los términos en que se realizan las solicitudes ante la Real Audiencia, como en el caso del señor Luis Tadeo Jiménez donde se puede apreciar la ritualidad de la solicitud, el lenguaje forense y los anexos documentales que se agregan a los expedientes:

(folio001) Testimonio de los documentos presentados por Don Luis Tadeo Jimenez

10 Doscientos Años del Colegio de Abogados de Cáceres. Miguel Martín Jiménez de Mañana. Archivo-Biblioteca. Diputación Provincial de Cáceres. Época IV. Número 46. Enero-Abril 1999. Índice. 1999-2008. Revista Alcántara.hptt/ab.dip-aceres.org/alcantara/alcan013. htm-199k consultada, marzo 18 de 2009.

11 Catálogos e índices. Médicos y Abogados. Archivo General de la Nación. República de Colombia. Bogotá: 1993, 64p. Ver listado anexo en el capítulo 5 sobre solicitudes de los abogados en la Real Audiencia.
Abogado de la Audiencia y Chancilleria de Santafé de Bogota Nuevo Reyno de Granada.

(Folio002)Sello segundo, seis reales, años de mil setecientos y setenta y dos, $y$ setenta $y$ tres.

Señor rector del Colegio Real Mayor de nuestra señora del Rosario $=$ Don Luis Javier Jimenez Colegial formal de el presento a los pies de s señoria, con mi mayor respeto y como mas haya lugar en que hecho digo: que para efectos de que me convienen, se hace servir su acreditada justificación mandar que el secretario de ese Colegio, me de testimonio de las informaciones, que produce para servir la veca, en que el excelentisimo Señor Virrey, se digno nombrarme que si es Justicia= Assia rendidamente suplico se sirva proveer como solicito yo Luis Tadeo Jimenez y Barragan =Santafe tres de Agosto, de mil setecientos(folio 003) que el Secretario de este Colegio, certifique en manera que haga fee, si consta en el Archivo de su cargo, haver yo usado de una de las Becas Seminarias de el, y si para ello hice contar mi mi legitimidad, limpieza y nobleza de Sangre como tambien, ser oriundo de la Villa de Honda, de donde son vecinos, mis Padres $=Y$ que asi mismo certifique si consta que yo fuere expulso de este colegio, o hiviere dado motivo para ello lo qual mediante assia. Rendidamente suplico se digne proveer como solicito yo Luis Tadeo Jimenes, y Barragan = Santafe $y$ Nobiembre dos, de mil setecientos setenta $y$ ocho $=$ como lo pide ay una rubrica $=$ Doctor Urive Secretario=informac. El doctor Don Pedro Urive, (?) secretario de este Colegio Real Mayor (folio004) Jimenez, y Barragan el clerigo de menores ordenes, y sacristán mayor de la ciudad de Mariquita puesto a los pies de S. senoria con el debido respeto digo: que para efectos que hacen a mi derecho se hace servir su acreditada Justificacion mandarseme de 
copia legalizada de mi fe de Bautismo que tengo presentada en esta curia, que en ello recibiré merced, y justicia la qual mediante As. señoria rendidamente suplico, se digne proveer como solicito que Juro en debida forma lo necesario va. Luis (decreto) Tadeo Jimenez y Barragan = Santafe catorce de Nobiembre, de mil setecientos, setenta y ocho = yo el notario hice saber el derecho de la buelta à Don Luis Tadeo Jimenez, en su persona doy fee Jimenez $=$ Robayo Notario = en cum ( folio 005) hijo legitimo de Don Luis Jimenez y Doña Florencia Barragan vino de un dia nacido, fue su padrino Don Bartholome Frutos, a quien adverti el parentesco, y obligación y para que conste lo firmo Doctor Don Miguel JosefVerastegui = Esta cierta y verdadera, y concuerda con la original de donde la saque, y para que conste doy la presente, $y$ firmo en Honda, a ocho de Agosto, de mil setecientos setenta y sinco años $=$ Doctor Don Josef Joaquin Tovar= concuerda con su original que se halla a la foxa, cuarenta, y quatro de los años que se hallan en este archivo de mi cargo, sobre la capellania que fundo Doña Petronila Osorio, de donde se saco corrigió, y (folio 006).

En la solicitud de Luis Tadeo Jiménez y como consta su declaración ante notario, encontramos los elementos de orden personal, social y genealógicos que prueban su pureza de sangre, la condición de hijo legítimo de sus padres, con reconocimiento en su provincia de origen, la declaración disciplinaria donde se da fe de su buen comportamiento como colegial, los testimonios y las constancias documentales que se allegan para reforzar su dicho.

\section{EL EXCESO DE ABOGADOS EN EL NUEVO REYNO DE GRANADA}

En contraste con el número de solicitudes para ejercer la profesión en la Real Audiencia y en las Chancillerías, y en virtud de las implicaciones que ello tiene al momento de revisar la idoneidad de los profesionales, frente a prácticas como la compra de títulos o la laxitud en la formación, está el hecho del creciente número de abogados como un problema sobre el cual la corona debe tomar medidas. El informe del fiscal Francisco Moreno, pone en evidencia el problema del manejo entre el poder secular y el clero, frente al otorgamiento de títulos y la necesidad de una universidad pública, como una herramienta de control frente a los excesos de las diferentes órdenes religiosas encargadas de la formación:

(...) Que con ocasión de estar despachando la fiscalía, y haber pedido en la Real Audiencia se limitase el crecido número de Abogados, obligándoles á la practica forense por cuatro años y sujetándolos á rigoroso examen en calidad y literatura, no satisfecho el celo de aquel regio Senado con haber proveído de oportuno remedio á este daño, conociendo que el origen dimana del disimulo con que admitiendo indebidos cursos se confieren los grados en la Universidad, sin el tiempo necesario; mandó volver el expediente al fiscal con orden de que instituyéndose las Constituciones de otra Universidad, pidiese lo correspondiente en remedio de este abuso, y demás decorosa estimación de los graduados.

Solicitadas las Constituciones no han sido habidas, ni persona que pueda dar razón de que en algún tiempo se formasen; $y$ aunque elD.P. Ror. Expuso que después del extrañamiento se hicieron una y remitieron para su aprobación á España; pero ni copia de ellas se reservó, ni parece que se han tenido otro Norte para la colocación de grados y manejo de este cuerpo literario, que la tradición, y confusa memoria de lo pasado; Por lo que se vió la Real Audiencia en la precisa necesidad de mandar que hasta la resolución de V.M S.M. se (Folio 1v) guarden las Constituciones de Lima que requieren cinco cursos para el grado bajo el reato de nulidad y que se formase $y$ remitiese por otro P.R. una especifica regulación de la cantidad que por cada 
grado deba contribuírse, reservando en su vista proveer lo demás á que se excitó su atención (?) deseosa del mayor provecho del bien común; franqueando al Fiscal Protector los testimonios que pidió no sólo para dar cuenta á S.M. como lo ha verificado, sino también para presentarlo en esta junta, á consecuencia del pensamiento que propuso sobre, lo útil y necesario de la creación de Universidad pública, y estudios generales en esta capital con que y no de otro modo se cortará radicalmente el desorden (...) (Moreno y Escandón, 1771, 25 de Octubre) ${ }^{12}$

Las quejas continuarían en los años siguientes, en la percepción de algunos funcionarios y cronistas de la época, el estado de la cuestión era motivo de preocupación y se exigían medidas a los monarcas para conjurarla. En la descripción del reino de Francisco Silvestre, uno de los puntos del informe es su enumeración de los aspectos sobre los cuales el monarca debía intervenir y uno de ellos es, justamente, sobre el creciente número de abogados:

207. El no permitir tanto número de Abogados, y fijar aquel según las poblaciones; y el pagar de las Rentas públicas los que debieran permitirse, para que no faltarian arbitros: desterrando todos los Comentadores de las Leyes, y sus opiniones, ciñendose al Código legal en los casos claros, y según su sentido literal, y en los dudosos, consultando al Principe en los negocios graves, para que la natural $y$ sencilla razon tubiese mas parte en la defensa, y en los juicios, y estos fuesen mas prontos, y con menor dispendio de las partes, sobre que podrían proponerse algunas reglas oportunas seria la felicidad de los pueblos, aun que parezca empeño de la mayor consecuencia; igualmente que la

12 Documento sobre el exceso de Abogados, Francisco Antonio Moreno y Escandón, Santa Fé de Bogotá 26 de Octubre de 1771, miscelánea 57. Bogotá: Biblioteca Luis Ángel Arango, Libros raros y manuscritos. Transcripción del documento manuscrito, conforme al original. Texto completo en anexo. supresión de todos los fueros privilegiados, que solo sirven de multiplicar los pleitos, $y$ tribunales, y de dificultar la Administracion de Justicia, en perjuicio gral. de Vasallos, y de la Jurisdiccion Real, que en lo Temporal y civil es la única que debe governar en un Estado; como que las Leyes son unas, $y$ a todos igualmente deben comprender, aunque modificadas en algunos casos y circunstancias (...) (Silvestre, 1789) ${ }^{13}$

En la colonia neogranadina no son extrañas tales preocupaciones, el tema del número de abogados, bien por su exceso o su defecto, ha sido tema de reflexión moderna y un asunto que inquietaba a las autoridades reales y a las Audiencias, y que puede apreciarse en las solicitudes de Ingreso de abogados para ejercer el oficio ante la Real Audiencia de Santafé. Las restricciones no eran solamente al proceso de formación y posterior expedición de títulos, el asunto giraba alrededor de las prohibiciones para la llegada de los juristas al nuevo mundo, como consta en la Orden Real a los oficiales de la Casa de Contratación de Sevilla, en 1509:

Porque no ha segdo informado que a cabsa de aver pasado a las Indias algunos letrados abogados han subcedido en ellas muchos pleitos e diferencias yo vos mando de que aquí adelante no deseéis ni consintays pasar a las Indias ningún letrado abogado sin vuestra licencia e especial mandado que sy necesario es por esta presente Cédula lo vendamos e proyvimos. ${ }^{14}$

Sin embargo, en un documento sobre el Estado del virreinato elaborado por el entonces Fiscal

13 Op.cit. Descripción del Reyno de Santa Fe de Bogota, escrita en 1789 por D. Francisco Silvestre, Secretario que fue del Virreinato y antiguo Gobernador de la Provincia de Antioquia. Copiada del original que se encuentra en Sevilla, en el Archivo General de Indias, por Ricardo S. Pereira 1887, Cap. XIII Remedios oportunos que necesita para sanar de sus males políticos. p.226.

14 Op.cit Rafael Domínguez. Galeria Universitaria p.49, Parra León Hermanos-editores. En: Chiossone Tulio. Formación jurídica de Venezuela en la colonia. 
protector Moreno y Escandón en el año de 1772, expresaba que existía retraso en el trámite de los juicios por el escaso número de jueces y dependientes de la Real Audiencia, después de la supresión de la Audiencia de Panamá en 1752 , planteando un contraste entre el número de abogados que ejercían el oficio como litigantes, frente a los que optaban por la magistratura civil:

Se padece atraso en el despacho de causas. Como sobre este escaso número de ministros; Subalternos recae el grave peso de los muchos i arduos negocios de justicia, que se han aumentado después de extinguida la Audiencia de Panamá, cuyas apelaciones vienen a esta pretorial, i al mismo tiempo deben los ministros acudir al despacho del juzgado general de la bienes de difuntos, al de provincia, juntas de real hacienda, extraordinarias, remates, comisiones, i votos consultivos al Superior Gobierno, padece notable atraso la administración de Justicia; demorándose, no obstante el clamor de los interesados, el seguimiento i determinación de las causas, i eternizándose los reos en los calabozos de presion, a que es consiguiente el desórden de los jueces inferiores, sobre cuya conducta no se puede velar con la vijilancia que es debida para contenerlos en los limites de lo justo, supuesto que a la Audiencia aun le falta tiempo para dar vado a las causas pendientes; consistiendo tambien en que casi todos los ministros son de avanzada edad; padecen continuas dolencias idemas funciones peculiares al ministerio de alcaldes de corte que ejercen, sino tambien al incesante desvelo que se requiere; de que en muchas causas de justicia acuden al Superior Gobierno, embarazándoles la atención a otros importantes objetos del mando $(. . .)^{15}$

15 Estado del Virreinato de Santa Fe, Nuevo Reino de Granada I Relacion de su gobierno i mando del excelentisimo señor Bailio frey don Pedro Mesia de la Cerda (...) por el D.D. Francisco Antonio Moreno i Escandon, Fiscal protector de Indios en dicha real Audiencia, Juez i conservador de Rentas Reales. Año de 1772. Texto manuscrito en Biblioteca Luis Ángel Arango, Bogotá. Sección de libros raros y manuscritos.
Queda claro que la preocupación sobre la cantidad de juristas, no correspondía con el número de ellos que se ocuparan de la magistratura en las Reales Audiencias, en tanto muchos abogados litigantes llevaban los casos pendientes para fallo y este número parecía ser considerablemente mayor al de los jueces en ejercicio.

\section{BIBLIOGRAFÍA}

AGUDO RUÍZ, Alfonso. Abogacía y abogados un estudio histórico jurídico. Editorial Universidad de la Rioja, 1997, 288pp.

ALEJANDRE GARCÍA, Juan Antonio. Un paréntesis en la Censura Inquisitorial de libros y folletos: lecturas en la España del trienio Liberal. En: Cuadernos de Historia del derecho. Madrid, 2003, no.10, 9-47pp.

ALMARZA VILLALOBOS, Ángel. La limpieza de sangre en el Colegio de Abogados de Caracas a finales del siglo XVIII. En: Fronteras de la Historia, Bogotá: ICAH, no. 10, 2005

ALTAMIRANO, Carlos. (Director) MYERS, Jorge (editor) Historia de los intelectuales en América latina. La ciudad letrada, de la conquista al modernismo. Buenos Aires: Katz editores, 2008

BAADE, Hans W. El número de abogados y escribanos en la Nueva España, la provincia de Texas y la Luisiana

BARCIA LAGO, Modesto. Abogacía y ciudadanía. Madrid: Ed.Dykinson, 2006

BARRIO MOYA, José Luis. Libros jurídicos en la carta de dote del abogado cántabro $\mathrm{D}$. Bartolomé Tejo de la Corte (1747). En: Anuario Jurídico y Económico Escurialense, 2005, tomo XXXVIII, 670-684pp.

Los libros jurídicos de D. Bernardo Fernández de Velasco. XI Duque de Frías (1771) En: Anuario Jurídico y Económico Escurialense, 2006, tomo XXXIX, 772-830pp.

CHARTIER, Roger. El orden de los libros. Lectores, autores, bibliotecas en Europa entre los siglos XIV y XVIII. Barcelona: Gedisa, 2000, 108pp. 
Historia o lectura del tiempo.

Barcelona: Gedisa, 2007, 93pp.

CLAVERO, Bartolomé. Historia del derecho: derecho común. Salamanca: Ediciones Universidad de Salamanca, 1994, reimpresión

Circulares, y Autos acordados, publicados y expedidos en el reynado del señor D. Carlos III. Madrid: En la imprenta de la viuda e hijo de Marín, 1793

CHIOSSONE, Tulio. Formación Jurídica de Venezuela en la Colonia y la República. Caracas: Universidad Central de Venezuela, 1980

COLLANTES DE TERÁN, Ma. José. Censura inquisitorial y devociones populares en el siglo XVIII. En: Revista de la Inquisición, 2001, no.10, 75-164 pp.

COLMENARES, German. Relaciones e informes de los Gobernantes de la Nueva Granada. 3 Tomos. Bogotá: Biblioteca Banco Popular, 1989.

CUENA BOY, Francisco. Teoría y práctica de la ley. Apuntes sobre tres juristas indianos. En: Cuadernos de Historia del derecho. No.13, 2006, 11-29 pp.

DESOLANO, Francisco. Reformismo y cultura intelectual. La biblioteca privada de José de Gálvez, Ministro de Indias. Universidad Complutense de Madrid. CSIC. Instituto "Fernández de Oviedo" Madrid.

Fuentes para la historia Cultural: Libros y Bibliotecas de la América Colonial. Anexo 1. En: Revista de Indias, 1984, 69-84pp.

DEL REY FAJARDO, José. Biblioteca de escritores jesuitas neogranadinos. Bogotá: Pontificia Universidad Javeriana, 2006.

La biblioteca Colonial de la Universidad Javeriana de Bogotà, Caracas. 2001, 865pp.

GAITÁNBOHÓRQUEZ, Julio. Huestes de Estado. La formación universitaria de los Juristas en los comienzos del Estado colombiano. Bogotá:
Colección Textos de Jurisprudencia. Universidad del Rosario. 2002, 323pp.

\section{Y MALAGÓN PINZÓN,}

Miguel. La "reducción a civilización" y otras técnicas de policia. Versiones historiográficas y prácticas administrativas de la Colonia a la República. En: Opinión Jurídica, 2008, Vol. 7, no 14 (julio/diciembre), 133-145pp.

GALENDE DIAZ, Juan Carlos. Las bibliotecas de los humanistas y el renacimiento. En: Revista de Información y Documentación. Madrid; 1996, vol.6, no.2, 91-123pp.

GARCÍA, Idalia. El conocimiento histórico del libro y la biblioteca novohispanos: representación de las fuentes originales. En: Información, Cultura y Sociedad. Buenos Aires, ciudad autónoma, 2007 (julio/diciembre)

GARRIDO, Margarita. Reclamos y representaciones. Variaciones sobre la política en el Nuevo Reino de Granada 1770-1815. Bogotá: Banco de la República, 1993

GIBERT, Rafael. La historia del derecho como historia de los libros jurídicos. En: I Seminario de historia del derecho y derecho privado. Edición a cargo de Joaquín Cerdá y Ruiz-Fines, Pablo Salvador Coderch. Universidad Autónoma de Barcelona, Bellaterra, 1985, 61-92pp.

GIRALDO JARAMILLO, Gabriel. El libro y la imprenta en la cultura colombiana: En: Incunables Bogotanos siglo XVIII. Bogotá: Banco de la República. Biblioteca Luis Ángel Arango, 1959, 237pp.

GONZÁLEZ, Margarita. El vasallo instruido en el estado del Nuevo Reino de Granada y en sus respectivas obligaciones. Bogotá: Universidad Nacional de Colombia, 2001, 408pp.

GONZÁLEZ M., Rosa. Abogados de la Real Chancillería y Catedráticos en Valladolid. Permanencias y cambios en las élites de poder (S.XVIII)

CASTRO GÓMEZ, Santiago. La postcolonialidad explicada a los niños. Bogotá: Universidad Javeriana, Instituto Pensar, 2005 
GÓMEZHOYOS, Rafael. La revolución Granadina de 1810. Ideario de una generación y de una época 1781-1821. Bogotá: Instituto Colombiano de Cultura Hispánica. 2 tomos, 1982

GOMÉZ-RIVERO, Ricardo. Los consejeros de la Suprema en el siglo XVIII. En: Revista de la Inquisición, Madrid, 1998, no.7, 165-224pp.

GUERRERO. Omar. Las ciencias de la administración en el Estado absolutista. La teoría de administración pública en las ciecias camerales $y$ en doctrina de la Policia en Europa entre los siglos XVI y XVIII. México: ed. Fontanamara, 1986, 360pp.

GUTIERREZ PONCE, Ignacio. Las crónicas de mi hogar o apuntes para la historia de Santafé de Bogotá. En: Papel Periódico Ilustrado. Bogotá, Imprenta de Silvestre y Compañía, 1883-1884

HAZARD, Paul. El pensamiento europeo en el siglo XVIII. Madrid: 1946

HERNANDEZ DE ALBA, Guillermo, et al. Una biblioteca de Santa Fe de Bogotá en el siglo XVII. Bogotá: Instituto Caro y Cuervo, 1960, 52pp.

HAZARD, Paul. El pensamiento europeo en el siglo XVIII. Madrid: 1946

HERNANDEZ DE ALBA, Guillermo, et al. Una biblioteca de Santa Fe de Bogotá en el siglo XVII. Bogotá: Instituto Caro y Cuervo, 1960, 52pp.

JARAMILLO J., Carlos Ignacio.El renacimiento de la cultura jurídica. El derecho en el medioevo siglos XI-XV. Bogotá: Pontificia Universidad Javeriana/ Temis, 2004, 651pp.

JARAMILLO URIBE, Jaime. Travesías por la historia (Antología). Bogotá: Biblioteca Familiar Presidencia de la República, 1997,425pp.

LEONARD A., Irving. Los libros del conquistador. México: Fondo de Cultura económica. 1996, 399pp.

LÓPEZ DURÁN, Rosalío. Sociología general y jurídica. México: Iure editores, 2005
LÓPEZ LEDESMA, Adriana. El derecho Prehispánico: Causa criminal en la Nueva España por acciones indecentes y sublevación indìgena. En: Cuadernos de historia del dercho, Madrid, no. 13, 2006 31-109pp.

MAJADA, Arturo. Oratoría Forense. Indicaciones históricas, Barcelona: Ed. Bosch, 1962

MALAGÓN P., Miguel. Vivir en Policía. Una contralectura de los orígenes del Derecho Administrativo colombiano. Bogotá: Universidad Externado de Colombia, 2007, 334pp.

MARIAS, Julián. España inteligible. Razón histórica de las Españas. Madrid: Alianza Universidad, 1985, 421pp.

MARSAL Y MARCE, José M. Síntesis Histórica del Derecho Español y del Indiano. Bogotá: Bibliográfica colombiana, 1959, 335pp.

MILLARES CARLO, Agustín. Cuatro estudios biobibliogràficos mexicanos. México: FCE, 1986, 462pp.

MINGUIJÓN ADRÍAN, Salvador. Historia del Derecho Español. Barcelona: Labor, 1933, 476pp.

MURO OREJON, Antonio. Cedulario Americano del siglo XVIII. Cédulas de Carlos II (1679- 1700) Sevilla: 1956.

PÉREZ PERDOMO, Rogelio. Los abogados de América Latina. Una introducción histórica. Bogotá: Universidad Externado de Colombia, 2004, 259p.

PRIETO Y SOTELO, Antonio. Historia del Derecho Real de España. Madrid: Antonio Sanz, 1739, $514 \mathrm{pp}$.

QUEVEDO, Francisco. Manuscritos teológicofilosóficos coloniales santafereños. En: Pontificia Universitas Xaveriana, Bogotá, 1962

RAMA, Angel. La ciudad letrada. Montevideo: ed. Arca, 1998, 126pp.

RIVAS SACCONI, José Manuel. El latín en Colombia. Bosquejo histórico del humanismo 
colombiano. Bogotá: Instituto Caro y Cuervo, 1993, 483pp.

ROCA ROCA, Eduardo. América en el ordenamiento jurídico de las Cortes de Cádiz. Bogotá: Universidad del Rosario, 1999, 183pp.

RODRÍGUEZ CRUZ, Agueda. Historia de la Universidades hispanoamericanas. Periodo Hispánico. Tomos 1 y 2, Bogotá: 1973

ROMERO, José Luis. Latinoamerica, las ciudades y las ideas. Medellín: Universidad de Antioquía, 1999.

ROS GARCÍA, Juan. La transmisión científica en el siglo XVIII. El Padre Feijoo. En: Documentación de las Ciencias de la Información, Madrid, no. 14, 1991, 45-68 pp.

SÁNCHEZ, Santos. Extracto puntual de las pragmáticas, cedulas, provisiones, Circulares, y Autos acordados, publicados y expedidos en el reynado del señor D. Carlos III. Madrid: 1973

SEMPERE Y GUARINOS, Juan. Historia del Derecho Español. Barcelona: Imprenta de Ramón Martín Indar, 1847, 460pp.

SOTO ARANGO, Diana. La ilustración en las universidades y colegios mayores de Santafé, Quito y Caracas. Estudio Bibliográfico y de
Fuentes. Bogotá: Colciencias, Universidad Pedagógica Nacional CIUP, 1994, 386pp.

La Reforma del Plan de Estudios del Fiscal Moreno y Escandón 1774-1779. Bogotá: Universidad del Rosario, 2004, 166p

URIBE ANGEL, Jorge. Historia de la enseñanza en el Colegio Mayor del Rosario 1653-1767. Cuadernos para la historia del Colegio mayor de Nuestra Señora del Rosario, Bogotá: Universidad del Rosario, 2003, 211pp.

URIBE URÁN, Víctor Manuel. Preparando "mandarines. Apuntes sobre la historia de la ciencia administrativa y su enseñanza en Nueva Granada durante la Colonia y comienzos de la República, 1590-1850. En: Revista Innovar. Universidad Nacional de Colombia, 1996, no.7 (enero-junio), 87-97pp.

Honorable lives. Lawyers, Family, and Politics in Colombia, 1780-1850. Pittsburg, 2000, 276pp. Edición en español: Vidas honorables. Abogados, Familia y política en Colombia 1780-1850. Bogotá: Fondo editorial EAFIT, Banco de la República, 2008, 441p.

ZUDAIRE HUARTE, Eulogio. Por los rumbos de la ilustración con el virrey Guirior. En : Quinto centenario, Madrid, 1986 